\title{
Incidence and duration of total occlusion of the radial artery in newborn infants after catheter removal
}

\author{
W.W.M.Hack ${ }^{1}$, A.Vos ${ }^{2}$, J.van der Lei ${ }^{3}$, and A.Okken ${ }^{1}$ \\ ${ }^{1}$ Department of Paediatrics, Division of Neonatology, ${ }^{2}$ Department of Paediatric Surgery, University Hospital, Free University, \\ DeBoelelaan 1117, 1007 MB Amsterdam, The Netherlands \\ ${ }^{3}$ Department of Medical Informatics, Erasmus University, Rotterdam, The Netherlands
}

\begin{abstract}
The incidence and duration of total occlusion of the radial artery after catheter removal was determined using repeated Doppler flow measurements. Thirty-two newborn infants with birthweights ranging from $945 \mathrm{~g}$ to $3890 \mathrm{~g}$ (median $1935 \mathrm{~g}$ ) and gestational age ranging from 26 to 40 weeks (median 32 weeks) were studied. In 20 out of 32 infants (63\%), complete occlusion of the radial artery occurred. The number of occlusions were not related to birthweight, gestational age or duration of cannulation. In all infants, blood flow in the radial artery resumed within 1-29 days after catheter removal. The duration of occlusion was directly related to the duration of cannulation and inversely related to birthweight.

This study demonstrates a high frequency of total occlusion of the radial artery in newborn infants after percutaneous radial artery cannulation. In the majority of infants with a radial artery catheter, blood flow to the tissue distal to the cannulation site is dependent solely on the existence of an adequate arterial palmar collateral circulation.
\end{abstract}

Key words: Percutaneous radial artery cannulation - Newborn infants - Radial artery occlusion

\section{Introduction}

In newborn infants requiring neonatal intensive care, cannulation of the radial artery is often necessary $[13,18,19,21]$. This enables continuous measurement of arterial blood pressure and facilitates repeated arterial blood sampling. Adverse sequelae include ischaemic damage to the hand, which, among other factors, is caused by thrombosis occluding the radial artery if the palmar collateral circulation is inadequate $[6,11]$. In adults and children, post-decannulation occlusion of the radial artery has been found in $8 \%-38 \%$ of cases $[4,8,9,12,15,20,23]$. Factors predisposing to arterial occlusion include duration of cannulation and external diameter of the catheter relative to the size of the vessel.

In newborn infants, where peripheral vessel diameters are small, a $70 \%-80 \%$ incidence of vessel occlusion has been detected by palpation after catheter removal $[1,3]$. However, palpation is inaccurate and despite vessel occlusion, a pulse may be detected originating from collateral flow $[4,15]$. Therefore, we determined the frequency and duration of total occlu-

Offprint requests to: W. W. M. Hack sion of the radial artery in newborn infants using a Doppler flow velocity meter.

\section{Methods}

We studied 32 newborn infants who were admitted to the neonatal intensive care nursery requiring arterial cannulation. Birthweights ranged from $945 \mathrm{~g}$ to $3890 \mathrm{~g}$ (median $1935 \mathrm{~g}$ ), being less than $2000 \mathrm{~g}$ in 16 infants. Gestational age ranged from 26 to 40 weeks (median 32 weeks) and was less than 33 weeks in 20 infants. Indication for intensive care included idiopathic respiratory distress syndrome in 18 , wet lung in 4 and congenital anomalies requiring major surgery in 6 infants. The majority were mechanically ventilated.

In all infants, the radial artery of the right or left hand was percutaneously cannulated by direct technique with a 24 gauge Teflon catheter (Quickath Baxtee B.V., Utrecht, The Netherlands, length $16 \mathrm{~mm}$ ) using transillumination [7, 17]. A cutdown procedure was not performed. Prior to cannulation the palmar collateral circulation had to be adequate. After insertion, the catheter was fixed to the skin with adhesive tape and connected to an arterial pressure line filled with heparinized $0.9 \%$ saline (1-5 units per $\mathrm{ml}$ ) solution. This solution was continuously infused and also used to flush the catheter after blood sampling. No other fluids or medications were given through the catheter, as this is associated with an increased risk of thrombosis $[1,22]$. Catheters were removed when no longer required, when signs of thrombosis or clotting of blood in the catheter occurred, or when catheter-related complications, such as septicaemia or ischaemia, appeared.

Blood flow in the radial artery was studied with a bidirectional Doppler ultrasonic flow meter (Medasonics model D-10, Laméris Instrumenten B.V., Utrecht, The Netherlands) with a $10 \mathrm{MHz}$ pencil probe (Medasonics model P95A). The signal was recorded on a two channel recorder (Medasonics model $\mathrm{R}-250$ ). To find the optimal position of the probe the audio signal of the machine was used [16].

Blood flow studies in the radial artery were performed as follows (Fig. 1): to obtain a maximal signal the pencil probe was placed on the radial artery, on the wrist at an angle of $45^{\circ}$, the tip of the probe being directed towards the elbow. In this way pulsatile flow towards the probe was obtained which resulted in an upward deflection on the recorder (Fig. 1a). Patency of the artery was assumed if pulsatile foreward flow was present. Occlusion of the radial artery was assumed when the 

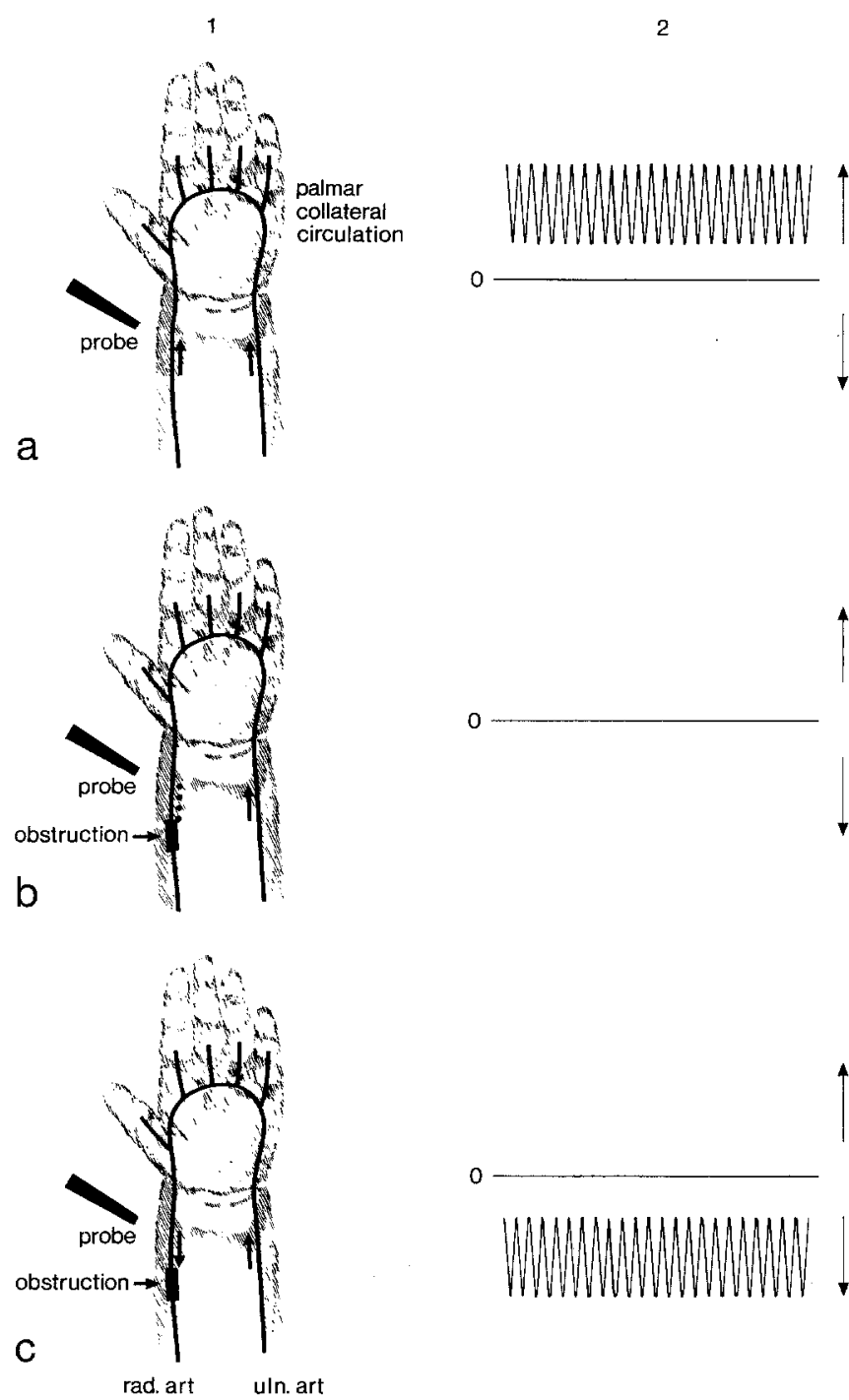

Fig.1a-c. Schematic drawing showing the detection of total occlusion of the radial artery by Doppler flow technique (1) with corresponding recordings (2). The probe is placed on the wrist thereby obtaining pulsatile foreward flow in the non-occluded artery (a). If the radial artery is completely occluded, no pulsatile flow distal to the puncture site is obtained (b). Occasionally total obstruction is detected by the presence of pulsatile retrograde flow through the patent palmar arches (c). $\mathrm{Rad}$ art, radial artery; uln art, ulnar artery; pulsatile foreward $(\uparrow)$ flow and retrograde $(\downarrow)$ flow

pulsatile foreward flow was absent (Fig. 1b) or when a retrograde flow was present; seen as a downward deflection on the recorder (Fig. 1c). Retrograde flow can sometimes be seen in cases of total occlusion of the radial artery if the palmar arches are patent.

Flow studies were carried out immediately prior to cannulation of the artery and within $24 \mathrm{~h}$ but not before $5 \mathrm{~h}$ after removal of the catheter. Post-decannulation flow was studied daily until pulsatile foreward flow was obtained for 2 consecutive days.

The median duration of the 32 cannulations was $54.5 \mathrm{~h}$ with a minimum of $5 \mathrm{~h}$ and a maximum of $464 \mathrm{~h}$.

Statistical significance of differences in birthweight, gestational age and duration of cannulation were analysed using the Student $t$-test for the presence or the absence of arterial occlusion. The coefficient of correlation was used to analyse the duration of occlusion in relation to birthweight, gestational age
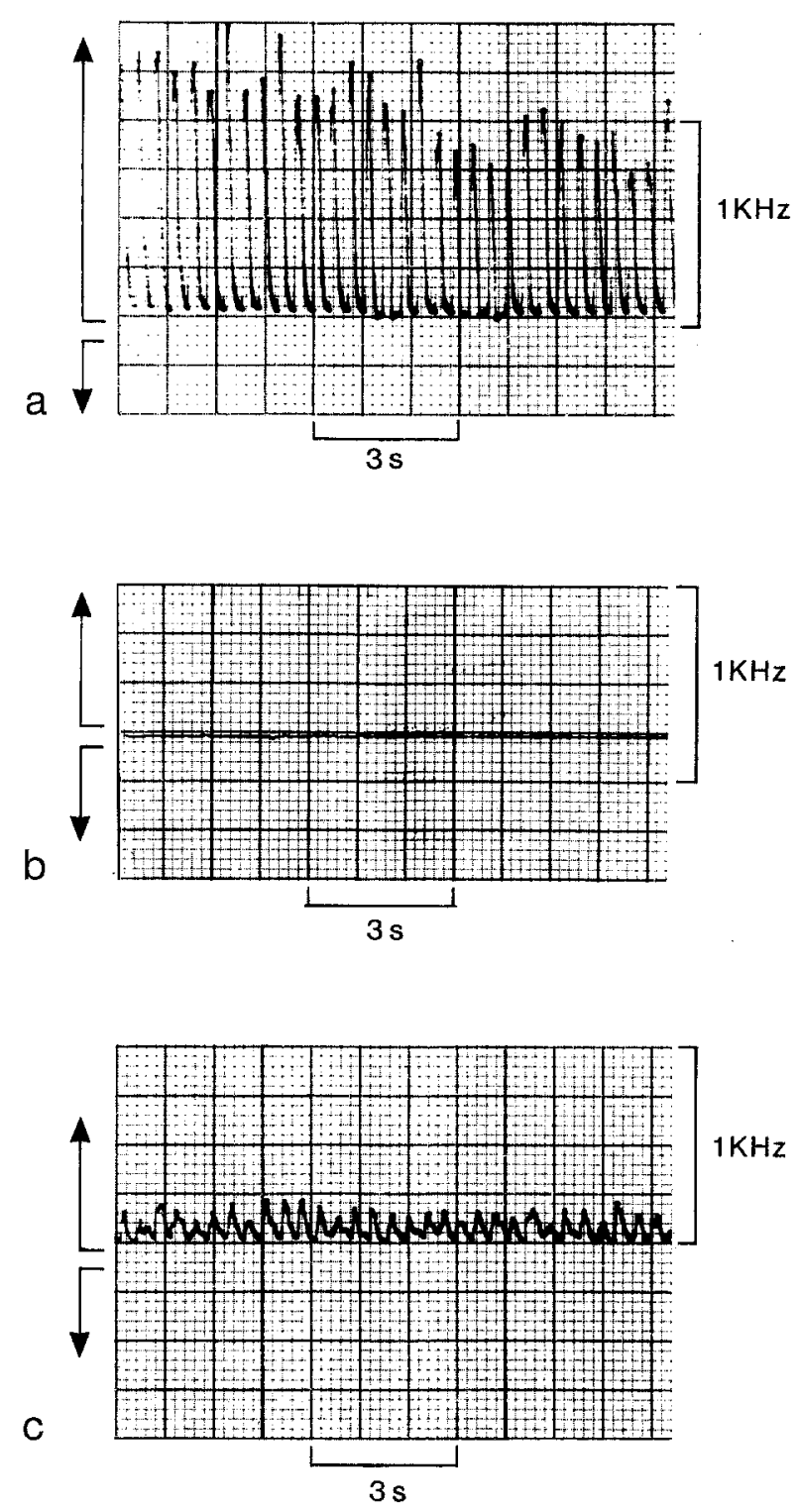

Fig. 2. Blood flow velocity recording in the radial artery obtained prior to cannulation (a). One day after removal of the catheter no pulsatile flow is detected indicating total occlusion of the radial artery (b). Four days after decannulation blood flow reappears (c). The decreased intensity of the Doppler flow signal is related to residual stenosis in the artery

and duration of cannulation. Statistical significance was defined by $P<0.05$. The study protocol was approved by the ethical committee of the hospital.

\section{Results}

A representative recording of the blood flow in the radial artery prior to cannulation is shown in Fig. 2a. Within $24 \mathrm{~h}$ after catheter removal, no flow was detected (Fig. 2b). Figure 2c shows the reappearance of blood flow.

In 20 out of 32 infants $(63 \%)$, total occlusion of the radial artery was found. As shown in Table 1, no significant correlation was found between arterial occlusion, birthweight, gestational age or duration of cannulation. In the majority of infants, total occlusion was indicated by the absence of pulsatile foreward flow. Retrograde flow was rarely documented. 
Table 1. Total occlusion of the radial artery after decannulation, number on infants, birth weight $(\mathrm{g})$, gestational age $(\mathrm{wk})$ and duration of cannulation $(\mathrm{h})$

\begin{tabular}{|c|c|c|c|c|}
\hline Radial artery & $\begin{array}{l}\text { Number } \\
\text { of infants } \\
(n=32)\end{array}$ & $\begin{array}{l}\text { Birth weight } \\
\text { (g) }\end{array}$ & $\begin{array}{l}\text { Gestational } \\
\text { age } \\
\text { (weeks) }\end{array}$ & $\begin{array}{l}\text { Duration of } \\
\text { cannulation } \\
\text { (h) }\end{array}$ \\
\hline Occlusion & 20 & $\begin{array}{l}1815 \\
(945-3200)\end{array}$ & $\begin{array}{c}32 \\
(26-40)\end{array}$ & $\begin{array}{l}56 \\
(5-264)\end{array}$ \\
\hline \multirow[t]{2}{*}{ No occlusion } & 12 & $\begin{array}{l}2225 \\
(1170-3890)\end{array}$ & $\begin{array}{c}32 \\
(28-40)\end{array}$ & $\begin{array}{l}43 \\
(5-464)\end{array}$ \\
\hline & $P$ & 0.30 & 0.84 & 0.80 \\
\hline
\end{tabular}

In all infants with total occlusion of the radial artery, blood flow reappeared within 1-29 days (median 6 days). The duration of occlusion as less than 6 days in 10 , between 6 and 10 days in 3 , between 11 and 15 days in 5 and between 16 and 29 days in 2 infants. No significant correlation was found between the duration of occlusion and gestational age $(P=0.18)$. However, there was a significant correlation, between duration of occlusion, duration of cannulation $(P=0.01)$ and birthweight $(P=0.046)$. Using stepwise regression, a significant correlation was established between the duration of occlusion and duration of cannulation, but not between the duration of occlusion and birthweight.

Once foreward flow was found, repeated studies at $24 \mathrm{~h}$ showed pulsatile foreward flow in all infants.

None of the 32 cannulations were associated at any time with clinical signs of permanent ischaemia of the forearm or the hand.

\section{Discussion}

Percutaneous cannulation of the radial artery has an integral role in the management of severely ill newborn infants. This technique permits continuous blood pressure monitoring and enables frequent arterial blood sampling. However, ischaemic damage of the hand with loss of tissue and function, sometimes requiring amputation, may occur particularly if the palmar collateral blood flow is inadequate $[2,6,10,11,13]$.

In children and adults the frequency of post-decannulation occlusion varies from $8 \%$ to $38 \%[4,5,8,9,12,14,15,23]$. Reappearance of blood flow in the occluded artery generally occurs, but may take several weeks. Duration of occlusion is related to the duration of cannulation $[4,9]$. The frequency of vascular occlusion is related to the relative size of the catheter $[8,15]$.

In the present study, a $63 \%$ incidence of total arterial occlusion was found in newborn infants. As in children and adults, the duration of occlusion in newborn infants was related to the duration of cannulation. In our study, birthweight was an additional factor, presumably because in low birthweight infants the period of cannulation was longer than in larger infants.

The higher frequency of post-decannulation occlusion of the radial artery in newborn infants may be an effect of the large external diameter of the catheter relative to that of the smaller radial artery. In addition, polycythaemia with resulting hypercoagulation is common in infants and may increase the likelihood of vascular occlusion. In this study, blood flow reappeared in all occluded arteries. However, in most infants the Doppler flow signal was markedly decreased once blood flow reappeared. This may indicate low post-stenotic blood flow velocity associated with residual stenosis in the artery. Long term follow up studies are needed to evaluate whether these partial occlusions eventually resolve.

Our studies indicate that post-decannulation occlusion of the radial artery is frequently encountered in young infants. To minimize the risk of ischaemia, proper evaluation of the arterial palmar collateral blood flow prior to cannulation is essential.

Acknowledgement. The help of Susan de Kok-Creech in preparing this manuscript is appreciated.

\section{References}

1. Adams JM, Rudolph AJ (1975) The use of indwelling radial catheters in neonates. Pediatrics 55:261-265

2. Adams JM, Speer ME, Rudolph AJ (1980) Bacterial colonization of radial artery catheters. Pediatrics 65:94-97

3. Barr PA, Sumners J, Wirtschafter D, Porter RC, Cassady G (1977) Percutaneous peripheral arterial cannulation in the neonate. Pediatrics 59 [Suppl]: 1058-1062

4. Bedford RF, Wollman H (1973) Complications of percutaneous radial-artery cannulation: an objective prospektive study in man. Anesthesiology $38: 228-236$

5. Brown AE, Sweeney DB, Lumley J (1969) Percutaneous radial artery cannulation. Anaesthesia $24: 532-536$

6. Cartwright GW, Schreiner RL (1980) Major complication secondary to percutaneous radial artery catheterization in the neonate. Pediatrics $65: 139-141$

7. Cole FS, Todres ID, Shannon DC (1978) Technique for percutaneous cannulation of the radial artery in the newborn infant. $J$ Pediatr 92:105-107

8. Downs JB, Rackstein AD, Klein EF, Hawkins IF (1973) Hazards of radial-artery catheterization. Anesthesiology 38:283-286

9. Evans PJD, Kerr JH (1975) Arterial occlusion after cannulation. Br Med J 3: 197-199

10. Heinonen K, Kuusela T (1982) Peripheral artery catheters in very low-birth-weight neonates. Acta Paediatr Scand 71:323-324

11. Hurt H (1984) Cosmetic defects. Peripheral arterial accidents. Clin Perinatol 11:219

12. Kim JM, Arakawa K, Bliss J (1975) Arterial cannulation: factors in the development of occlusion. Anesth Analg 54:836-841

13. Lin WJ, Baldomero A, Wei TJ, Kamtorn V, Sun S (1985) Pecutaneous peripheral arterial cannulation (PRAC) in neonates. Pediatr Res 19:196

14. Mandel MA, Dauchot PJ (1977) Radial artery cannulation in 1,000 patients: precautions and complications. J Hand Surg (Am) 2: 482-485

15. Marshall AG, Exwin DC, Wyse RKH, Hatch DJ (1984) Percutaneous arterial cannulation in children. Concurrent and subsequent adequacy of blood flow at the wrist. Anaesthesia 39:27-31

16. Morray JP, Brandford HG, Barnes LF, Oh SM, Furman EB (1984) Doppler-assisted radial artery cannulation in neonates and children. Anesth Analg 64:346-348

17. Pearse PG (1978) Percutaneous catheterization of the radial artery in newborn babies using transillumination. Arch Dis Child $53: 549-554$

18. Randel SN, Tsang BHL, Wung JT, Driscoll JM, James S (1987) Experience with percutaneous indwelling peripheral catheterization in neonates. Am J Dis Child 141:848-851

19. Riggs CD, Lister G (1987) Adverse occurrences in the pediatric intensive care unit. Pediatr Clin North Am 34:96-97

20. Ryan JF, Raines J, Dalton BC, Mathieu A (1973) Arterial dynamics of radial artery cannulation. Anesth Analg 52:1017-1025

21. Sellden H, Nilsson K, Larsson LE, Ekstrom JB (1987) Radial artery catheters in children and neonates: a prospective study. Crit Care Med 15:1106-1109

22. Wehbe MA, Moore JH (1985) Digital ischemia in the neonate following intravenous therapy. Pediatrics 76:99-103

23. Wilkins RG (1985) Radial artery cannulation and ischaemic damage: a review. Anaesthesia 40:896-899

Received January 24, 1989 / Accepted June 8, 1989 